\title{
La escritura de la rabia: Luisa Valenzuela y la mirada de la dictadura
}

\author{
Writing with anger: Luisa Valenzuela and her vision \\ of a dictatorial regime
}

\section{Claudia Cavallín Calanche}

Universidad Simón Bolívar, Caracas, Venezuela

ccavallin@gmail.com

- N EL AM PLÍSIM 0 espectro de textos que conforman el corpus de la litera— tura latinoamericana, existe un giro reciente, caracterizado por la emergencia de ciertos autores que, haciendo uso de varias de las funciones de autor propuestas por M ichel Foucault ${ }^{1}$, se pronuncian acerca del horror desde una mirada crítica.

Se trata de una escritura particular, que cuestiona las instituciones de poder y ordenamiento del Estado, a través de diversas voces que resaltan las características de ciertos sujetos que han sido objeto de prácticas de exclusión y otras aberraciones propias de la degeneración de los sistemas democráticos occidentales. En este estilo, se destaca la escritora argentina Luisa Valenzuela, quien propone una narrativa hiperconsciente de las situaciones de la mujer, los torturados, los disidentes y otros sujetos localizados al margen del poder, para formular una denuncia que parte de la rabia y la impotencia de saberse, al mismo tiempo,

\footnotetext{
${ }^{1}$ Siguiendo con la teoría de Foucault (1999) sobre los emplazamientos del autor, condiciones que posibilitan su función, tomaremos como relevante la "posición de autor" (es decir, cómo se relaciona ante los diferentes tipos de discursos), pues no se forma fortuitamente la atribución de un discurso a un individuo; se trata, como señala Pierre Bourdieu, de un proceso de intercambio de capitales simbólicos en donde la posición del autor (y ya no hablaríamos de espacio, sino de lugar) dentro de la jerarquía del campo cultural enfrenta a otras, y se mueve de acuerdo a ciertas reglas del juego. En el campo literario un autor con estas dimensiones tendría como función proponer nuevos discursos que no necesariamente lo convierten sólo en un sujeto discursivo, pues según Bourdieu sería más bien actor comprometido con el campo al cual ingresa, que se atreve a proponer un espacio para la disidencia y que sobrevive en su campo gracias a su capacidad de lucha y enfrentamiento con ciertas prácticas, pero no debido exclusivamente a condiciones concernientes a la originalidad, la maestría 0 a una autoridad legitimada por la academia (Foucault, 1999).
} 
narradora y protagonista, víctima y juez de la realidad/ficción presente en sus textos.

Todo esto es posible debido a su posicionamiento como autora excéntrica, lo cual le permite visualizar la realidad a través de una mirada sesgada, que se escapa de la censura y omite los convencionalismos. El resultado puede verseno sólo en la producción literaria deVal enzuela, sino en sus entrevistas, manifiestos e, incluso, en su conducta personal e imagen, pues se trata de enarbolar una posición de discurso que enfrenta al orden haciendo uso de fuerzas que impulsan una particular natural eza creativa, producto de sentimientos como la rabia, el odio, el desamor, la crueldad, presentes también en la occidentalidad misma.

En este caso, el protagonismo del autor le confiere un nuevo sentido a la pregunta foucaultiana del ¿qué importa quien habla? Esta interrogante se convierte en una pregunta central eindispensable para el estudio de escritores como Valenzuela, porque quien habla, en este caso, lo sigue haciendo desdela escritura misma pero también desde sí hacia el exterior. "En la escritura, no se trata de la manifestación o de la exaltación del gesto de escribir; no setrata dela sujeción de un sujeto a un lenguaje: se trata de la apertura de un espacio en donde el sujeto que escribe no deja de desaparecer" (Foucault, 1999: 102). La pregunta ¿quéimporta quien habla? y su indiferencia implícita constituye, según Foucault, el principio ético más fundamental de la escritura contemporánea.

Por otro lado, Luisa Valenzuela, desde una mirada benjaminiana, está proponiendo un discurso que cepilla la historia a contrapelo, es decir, tienela capacidad de leer su presente para anticiparseal futuro, de tal forma que lo que sería la interpretación lineal de los acontecimientos se invierte para privilegiar una lectura inversa del tiempo que permite prever lo impredecible. Dice Benjamin: "éste deberá ser el aspecto del ángel de la historia. $\mathrm{H}$ a vuelto el rostro hacia el pasado. D onde a nosotros se nos manifiesta una cadena de datos, él ve una catástrofeúnica que amontona incansablemente ruina sobre ruina, arrojándolas sobre sus pies. Bien quisiera él detenerse y despertar a los muertos y recomponer lo despedazado. Pero desde el paraíso sopla un huracán que se ha enredado en sus alas y que siendo tan fuerte el ángel no puede cerrarlas. Este huracán lo empuja irresistiblemente hacia el futuro, al cual da la espalda, mientras que los montones de ruinas crecen ante él hasta el cielo" (Benjamin, 1999: 54).

Tomando en cuenta estas condiciones, analizaremos las obras: Cola delagartija y Cambio dearmas², de Luisa Val enzuela, ambas publicadas por primera vez

\footnotetext{
${ }^{2}$ Cola de lagartija fue escrita en exilio norteamericano de la autora, en 1981, y su primera edición de 1983 fue realizada en Buenos Aires por Bruguera, y posteriormente reeditada en M éxico por la U N AM en 1992. La edición utilizada para esta nota es la de Norma, realizada en Buenos Aires, 2007. Cambio de armas, editada en 2005 por Editorial N orma, apareció por primera vez en
} 
en Estados U nidos, buscando establecer la ruta del discurso de la autora que permite confirmar la presunción de que, efectivamente, se trata de una narrativa diferente, marginal, excéntrica y profundamente sensible que, más que ajustarse a los valores canónicos de la industria literaria, se sirve de ellos para burlar cualquier mecanismo de censura -e incluso de autocensura- que contenga el torrente crítico de su escritura.

\section{LA ESPALD A AZOTADA POR LA COLA DE LAGARTIJA}

Luisa Valenzuela escribió Cola de lagartija en 1983, pero la historia que relata tiene su origen, a lo menos, diez años antes. Pocos meses después de la M asacre de Ezeiza, en octubre de 1973, Juan D omingo Perón gana las el ecciones argentinas con un $60 \%$ delos votos, y asume la Presidencia acompañado de su esposa I sabel M artínez de Perón como vicepresidenta. El tercer gobierno de Perón estuvo marcado, sin duda, por un incremento de la violencia descarnada, razón por la cual se crearon brigadas parapoliciales que contaban con el apoyo oficial. José López Rega (alias El Brujo), ministro de Bienestar Social, director de la Alianza Anticomunista Argentina (AAA) y secretario personal de Perón, se encargó de organizar y dirigir varias de ellas.

En esta novela, la autora apuesta por una narración tránsfuga que se inicia con la deformación física del personaje principal -El brujo-, y culmina con la aproximación del nefasto personaje a la propia conciencia de la narradora. D esde el lenguaje de la escritora (Valenzuela o Rulitos, en el texto), la compleja personalidad de López Rega se vuelve más real mientras más se aproxima a la ficción.

Representar la inaprensiblefigura de un dictador, desde la dictadura misma, resulta en extremo difícil, no sólo por la imposibilidad que dicta la censura propia de estos regímenes sino, además, porque las palabras para describir el horror y la cruel dad nunca son suficientes.

En Cola de lagartija (que inicialmente iba a ser Ilamada El brujo hormiga roja, Señor del Tacuru, Amo detambores, M inistro de Bienestar, Serruchero M ayor, Alto sacerdote del $D$ edo, Patrón de los desamparados, D ueño de La voz, y su hermana Estrella), novela y biografía se funden como géneros, pero también se confunden las voces narrativas, las experiencias de la autora y los periplos de López Rega; todo ello aprisionado en una intencionalidad creadora que intenta repro-

Estados U nidos, H anover, Ediciones del N orte. L os cuentos emigraron con la autora en 1979, pero no fueron publicados sino hasta entonces. 
ducir, en el libro, la sensación de saberse, al mismo tiempo, protagonista y espectadora de una de las dictaduras más férreas de América Latina. La voz resultante, más allá de una conciencia meramente reflexiva, realmente retrata las atrocidades cometidas por El Brujo y el ambiente que permitió, o al menos toleró, quela hechicería y la magia se convirtiesen en asuntos políticos de envergadura.

En los confines de la penumbra y la maldad, Valenzuela decide emplazar a un protagonista no menos oscuro. Sin embargo, ¿cómo hablar del horror sin concederlesu grandeza? La autora reconoce que, aun en este relato abominable, sería imposible transmitir la inconmensurabilidad de la violencia descarnada y los atropellos de la dictadura sin mencionar que se trata de algo superior a la medida de lo humano. Por esto, la figura de El Brujo es elevada y mitificada, en medio de un aura de magia y misterio. Entonces, ¿cómo narrar la magnitud de lo sucedido sin exaltarlo, sin condescender? Valenzuela resuelve la paradoja a través de una escritura en dos direcciones: una arbitrariamente biográfica, donde El Brujo puede transformarse a su antojo y otra autobiográfica, que sale al rescate de la conciencia en los momentos más terribles de la historia.

Como ella misma señala, en el único aparte que lleva su verdadero nombre como rúbrica, se trata de "ponerse a escribir cuando por ahí, quizás a un paso no más, están torturando, matando, y un apenas escribiendo como única posibilidad de contraataque, qué ironía, qué inutilidad. Q ué dolor, sobre todo. Si al detener mi mano pudiera detener otras manos. Si mi parálisis fuese, al menos, un poco contagiosa, pero no, yo me detengo y los otros siguen implacables, hurgando en los rincones, haciendo desaparecer a la gente, sin descanso ni justificación alguna, porque deeso setrata, demantener el terror y la opresión para que nadie se anime a levantar la cabeza" (Valenzuela, 2007: 249).

Pero no es una escritura inútil. Por el contrario, representa casi la única forma de darle cuerpo, rostro y voz a todo aquello que la opacidad de la censura nunca dejó traslucir. Un ejemplo de esta escritura se produce cuando Valenzuela se sirve del cuerpo del protagonista para metaforizar el cuerpo del terror y sus aberraciones. La autora le presenta al lector un ministro hermafrodita, sádico y enamorado de sí mismo, capaz de cometer el peor de los incestos para procrear en unión de la hermana inconclusa quelleva entrelas piernas. Esta sensación de estar frente a un ser capaz de imaginar semejante aberración y, sobre todo, con el poder suficiente para llevarla a cabo, por encima de toda muerte y sacrificio, probablemente sea lo más parecido al estupor que sintieron en su momento los cientos de torturadosy desaparecidos de la dictadura pues, para ellos, los límites de la realidad dejaron de existir en el mismo momento en que el poder y la maldad transformaron la dimensión de todo lo existente. D e este modo, la imagen de El Brujo en Cola de lagartija, probablemente se acerca mucho más a la 
auténtica, desde su condición de divinidad todopoderosa, que la visión realista de cualquier documento histórico o biográfico que sólo relate la vida de este cruel y mortal ministro de Bienestar Social.

En ocasión de la reedición de la novela en 2007, Valenzuela señaló que Cola delagartija "es el drama de querer tapar la parte oscura. A mí me interesa mirarla de frente, en lo posible, aunque siempre da miedo. Son locuras de cada uno de nosotros, y ese Brujo está en mí. Es el reconocimiento de que hay algo en todos nosotros y por eso permitimos que suceda (... ) Con Cola de lagartija me di cuenta de que respondía a la profecía con el cuerpo. Puede ser catártico a la larga, pero en ese momento hay que poner el cuerpo, el alma, y quemarse. Es mucha suerte cuando tenés esa oportunidad. No me ha sucedido muchas veces. O jalá me volviera a suceder, porque estoy dispuesta a jugarme entera por un libro, pero a veces los cuidados están ahí, a pesar deuno" (C arelli Lynch, 2007).

La autora exalta esta mirada particular que se enfrenta al mal y presume de ella, no sólo a través de la literatura, sino además en su discurso, puesúnicamente desviando la perceptiva hacia los lados nunca vistos se puede obtener una mirada frontal, cara a cara, ante el horror. Esta condición va más allá de una simple licencia literaria o diversión estilística; la posición de autor deValenzuela le ha facilitado una percepción de su realidad hipersensibilizada, al punto que, para al gunos, llega a ser profética, sobre todo después de Cola de lagartija.

Esta aseveración la sostienen aquellos que notaron cómo, años después, la historia reescribió el final de la novela de Valenzuela, con una exactitud pasmosa. López Rega murió años después, a la espera de su juicio, víctima de un cáncer en el testículo. Al enterarse de su muerte, la escritora comentó: "C uando llegó esa (noticia) tan fuerte, ya me había armado una idea racional del asunto, y pensaba, y pienso, que la narrativa encuentra un camino que la realidad cumple, porque la vida es una narrativa. Si uno es fiel a aquello queintuye, que se va componiendo sin forzar, encuentra un camino deprofecía" (C arelli Lynch, 2007).

\section{DESMEMORIA DEL HORROR}

Si no como profecía, al menos como alerta, está claro que el discurso de Luisa Valenzuela es incendiario y denuncia aspectos que develan, directamente, la degeneración de los valores de la sociedad y el maltrato a las minorías lejanas al poder. Cambio de armas, en todas sus líneas, es un grito desesperado de dolor que brota del inconsciente, pues no está registrado en la memoria y sólo puede leerse al intentar completar los espacios en blanco, los vacíos, las desapariciones, el mutismo, el olvido.

Valenzuela narra la desmemoria de una mujer víctima de las más terribles 
torturas, que se sumerge en el olvido y busca desesperadamente encontrar un sentido a su existencia de muñeca decorativa, bajo la tutela de un posesivo, enigmático y supuesto marido militar. Las imágenes son desgarradoras: la primera vez que ella se mira al espejo ve una espal da azotada, una cicatriz espesa, pero su memoria está bloqueada. El trato que su marido da a Laura es siniestro y un caso de horror. En la escena titulada "Los espejos", Laura está acostada boca arriba sobre la cama nupcial, donde el hombre ha colocado espejos para prolongar su placer al infinito. Con su cuerpo estremecido, Laura acepta el ritual de ser moldeada por él. En esta escena de ultrajey violencia, ella reacciona ambiguamente, en parte con deleite físico y en parte con un rechazo total de ese repugnante acto de amor, descrito por Valenzuela como "todo un estremecimiento deleitoso, tan al borde del dolor. M ientras él la insulta " ¡Abrí los ojos, puta!", ella grita un "No".

Lo interesante del discurso de la autora no está en el hecho de describir, de manera cruel y descarnada, un acto de violencia como aquéllos ocurridos en su país natal entre 1976 y 1983. El valor del texto estriba en que, para el momento desu publicación (1982), eran pocos, o casi nulos, los documentos que registraban con tal exactitud los abusos de poder perpetrados por la dictadura militar durante uno de los procesos más sangrientos que registra la historia argentina, donde muchas mujeres estudiantes, sindicalistas e intelectuales fueron secuestradas, asesinadas y desaparecidas.

Bajo el signo del horror, el cuerpo se somete a la más terrible de las mutilaciones: la amputación de la identidad. Laura no recuerda (no puede, no quiere recordar) quién es, sus sentimientos hacia el marido son ambiguos, más que amarle le teme. La razón es un tanto obvia para el lector: Laura ha sido torturada por su bienhechor hasta el punto de convertirla en un ser anónimo, en una posesión más del militar que se complace en someterla apenas con la mirada, pues ya nadie la obliga a permanecer allí, ya no hay rejas, ni prisiones, las puertas están abiertas - 0 al menos las Ilaves están a la vista- pero Laura es incapaz del más mínimo movimiento subversivo.

Aún sin recordar, Laura sabe suficiente. En los vacíos, el horror de la dictadura parece más presente. El miedo se aglutina y tieneun efecto paralizante. Sin embargo, es el final lo que verdaderamente da cuenta de la magnitud del daño producido en la joven mujer. ¿Por qué el conocer su identidad es devastador para Laura? ¿Por qué el cambio de armas no garantiza la conciliación con su existencia? U na vez más, la escritora desafía al lector: "Escribo contra aquellos que creen tener todas las respuestas. Espero que cada uno de mis libros sea un semillero de preguntas que genera más preguntas y por suerte casi ninguna respuesta (... ) Las mujeres sabemos mucho de esas cosas, es hora de que vayamos aprovechándolas para poder decir nuestra palabra, la palabra que hasta ahora 
nos estaba vedada (... ) Por medio del grotesco, de un hiperrealismo literario, del humor negro, de lo que fuere, logré pasar las barreras de la censura gubernamental y decir en ese momento lo que tenía que decir. Fue así como nació, bastante más adelante y luego de otros libros, Cambio dearmas y al gunos de los cuentos que integran la nueva colección: Simetrías"3.

Se cumple, entonces, lo que, para Foucault, es una de las principales funciones del autor: producir otros discursos a partir del propio. Valenzuela no es solamente la autora de su obra, de sus libros; ha producido algo extra: la posibilidad y la regla de formación de otros textos y discusiones a partir de las interrogantes que su escritura plantea. Esuna autora productora, no ya denovelas y cuentos, sino de capital simbólico cultural, que da cuenta de la narrativa del horror de la dictadura argentina y que refleja, de manera descarnada, las condiciones sociales de su producción. M ás concretamente, se trata de asumir una posición de escritura que determina, a la vez, por mediaciones diferentes, un particular interés expresivo, que evade la forma y la fuerza de la censura que se le impone.

Por ello, no podemos leer a Luisa Val enzuela sin tomar en cuenta que se trata de una autora que se presenta como sujeto de la acción (que registra una época, un pensamiento), a través de una escritura extravagante pero realista; que se transforma a través de personajes simbólicos mutantes y que registra un discurso como práctica que se mueve históricamente.

\section{REFEREN CIAS}

Benjamin, Walter. 1999. La dialéctica en suspenso. Fragmentossobrela historia. Traducción de Pablo O yarzún. Santiago, Chile: Lom Ediciones.

Carelli Lynch, Guido. 2007. "En ciertos momentos hay que poner el cuerpo, el alma y quemarse", entrevista a Luisa Valenzuela. Diario El Clarín, Argentina, 6 de agosto.

Foucault, M ichel. 1999 [1970]. "¿Qué es un autor?", en Literatura y conocimiento. M érida: Ediciones de la U niversidad de Los Andes.

Valenzuela, Luisa. 1991. "Escribir". D isponibleen: http://www. letrasdechile.cl/mambo/ index. php?option $=c 0 m \_c o n t e n t \&$ task $=v i e w \&$ id $=108 \&$ Itemid $=40$ [Acceso: 08.03.2008]

--- Cambio de armas. Buenos Aires: N orma.

--- Cola de lagartija. Buenos Aires: Norma.

${ }^{3}$ Declaración de la autora en su texto "Escribir", de 1991, publicado en distintos sitios de internet. [Consultado: 08.03.2008]. Disponible en: http://www.letrasdechile.cl/mambo/index. php?option=com_content $\&$ task=view $\&$ id $=108 \&$ I temid $=40$ 